\title{
RESEARCH PROGRESS OF SYNTHESIS OF DICLOFENAC SODIUM
}

\author{
Zhang kun, Liu Yanjie* \\ Jilin Institute of Chemical Technology, Cheng De Street No.45, Jilin, China. \\ *Corresponding Author Email: 523412972@qq.com
}

This is an open access article distributed under the Creative Commons Attribution License, which permits unrestricted use, distribution, and reproduction in any medium, provided the original work is properly cited

\section{ARTICLE DETAILS}

\section{Article History:}

Received 26 June 2018 Accepted 2 july 2018

Available online 1 August 2018

\begin{abstract}
This article mainly analyzes and describes the property and current development prospects of the third generation non-steroidal anti-inflammatory drug diclofenac sodium. And stressly introduce on some of its synthetic process routes. In addition, relevant information such as process conditions, raw material types, and factors affecting the yield of each synthesis route is specifically proposed. Finally, the defects of the synthesis process of diclofenac sodium and the development trend of its further research are described.
\end{abstract}

\section{KEYWORDS}

Diclofenac sodium, derivative, Synthesis, Process, Progress.

\section{Introduction of diclofenac drugs}

Diclofenac and ibuprofen are the main varieties in non-steroidal antiinflammatory drugs, and they always occupy $50 \%$ to $60 \%$ of the drug market. Moreover, diclofenac, as a new type of potent non-steroidal antiinflammatory drug, has been consistently ranked first in the non-steroidal anti-inflammatory drug market for more than ten years. Diclofenac had a market share of $27.4 \%$ in $1998,29.7 \%$ in 2001 , and is currently around $30 \%$. The main mechanism of these drugs is to inhibit the synthesis of inflammatory reaction, and thus it plays a role in relieving pain and relieving inflammation. These drugs are effective in relieving fever, relieving pain and eliminating inflammation, with fewer adverse reactions [1].

\subsection{Diclofenac}

Diclofenac is the main anti-inflammatory and analgesic effect of nonsteroidal anti-inflammatory drugs. Compared with other tricyclic nonsteroidal anti-inflammatory drugs, diclofenac has strong antiinflammatory and analgesic effects, and has good safety and tolerability. Diclofenac is a non-steroidal anti-inflammatory drug of phenylacetic acid. It was first developed by Giba-Geigy company and applied in clinical practice [2]. This type of drug has a broad market and is one of the most widely used non-steroidal drugs, and some researchers believe that diclofenac is an important representative drug in anti-inflammatory drugs. This type of drug has been listed with new drugs, indicating that this type of drug has the potential of remolding and modifying new drugs. Its structure is shown in Figure 1:

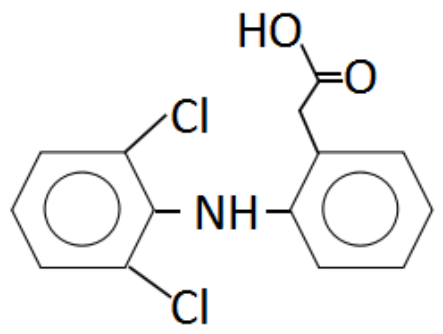

Figure 1: Structure of diclofenac

\subsection{Diclofenac sodium}

Diclofenac sodium, chemical name is sodium odichloroanilinophenylacetate, also known as diclofenac, and it is white crystalline powder, odorless, easily soluble in acetone, soluble in methanol and ethanol, slightly soluble in water, and it has hygroscopicity. Diclofenac sodium is the most important intermediate in diclofenac drugs. Because of its good anti-inflammatory and analgesic effect and safety, it is widely used in the clinical treatment of various arthritis and other joint pain, neuralgia, whole body pain and all kinds of inflammation caused by the fever effect is good, so it is the common anti-inflammatory drug in the market [2]. Its structural formula is shown in Figure 2:

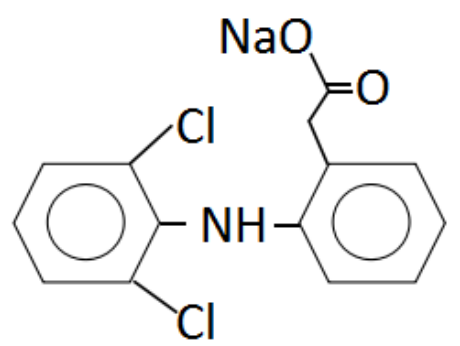

Figure 2: Structure of diclofenac sodium

\section{THE DEVELOPMENT PROSPECT OF DICLOFENAC SODIUM}

In 1984, the Guangzhou pharmaceutical industry studied o-chlorobenzene as a starting material, and diclofenac was successfully prepared through multi-step reactions such as chlorination, hydrogenation, hydrolysis, and condensation. In 1986, Guangzhou Mingxing Pharmaceutical Factory took the lead in the production of diclofenac and put the product on the market. Now, more than ten enterprises in China have produced diclofenac raw material. In recent years, the output of diclofenac in China has continuously increased, reaching 250 tons in 1999, 310 tons in 2000, and 420 tons in 2001. At present, the annual output of diclofenac in China is more than 600 tons, and the annual production capacity exceeds 1000 tons [3]. Today, there are more than 100 enterprises in the world that produce diclofenac, and the global market has an annual demand of more 
than 2,000 tons. This is mainly due to the following advantages of diclofenac products in their development [4,5]. First of all, it has the characteristics of strong clinical efficacy, fast distribution and rapid elimination in vivo. Second, there are huge market consumption groups. Third, the development of diclofenac derivatives has very broad prospects.

\section{RESEARCH TRENDS}

Although diclofenac products have good prospects for development, the production and technological conditions of the diclofenac are limited. The cost of domestic production has been higher than that of foreign countries, which limits the development of the domestic pharmaceutical industry. In addition, there are some side effects of diclofenac. Diclofenac sodium has a strong stimulatory effect on the digestive tract, and the incidence of adverse reactions after taking it is as high as $19.3 \%$ [6]. So a lot of work has been done at home and abroad for diclofenac, a lead compound, and related products such as diclofenac choline, diclofenac lysine salt and diclofenac methyl ester have been developed to reduce their side effects [7].

According to the literature, at present, the research on diclofenac sodium is often focused on its usage, indications, and dosage forms, and the research on its derivatives and structure-activity relationship has not been further studied [8]. We can study the structure-activity relationship by synthesizing diclofenac sodium derivatives and looking for a simple and feasible synthesis route to increase the yield of synthetic drugs, in order to further improve the antipyretic and analgesic effects of drugs, reduce toxic and side effects, and prolong their effects time, and lay the foundation for the development of high-efficiency, low-toxic, long-term non-steroidal anti-inflammatory drugs.

\section{SYNTHETIC ROUTE}

Since diclofenac was synthesized by Salman et al. in 1964, domestic and foreign scholars have conducted extensive research to improve their synthesis methods in order to increase productivity and reduce production costs. There are many kinds of synthetic methods reported at home and abroad at present, but there are five major types of synthetic methods, including o-halobenzoic acid, o-halophenylacetic acid, aromatic aldehydes or aryl ketones, fluorenone and other methods. Diclofenac sodium was first synthesized successfully in 1975, followed by German, French, English, Japanese, etc., and successfully put into the market $[9,10]$. There are many domestic and foreign documents on the preparation methods, which mainly include the following synthetic routes:

\subsection{Cyclohexanone Route}

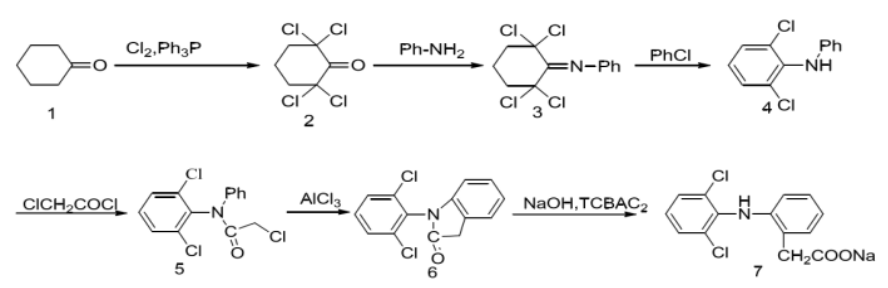

Figure 3: Route map for the synthesis of cyclohexanone

In this method, cyclohexanone in carbon tetrachloride solution is first used to generate compound 2 under the catalysis of triphenylphosphine. Then, Compound 3 was prepared by condensing Compound 2 with aniline using a strong dehydrating agent anhydrous titanium tetrachloride. Compound 3 was dehydrochlorinated by derivatization at $100^{\circ} \mathrm{C}$. and the reaction was carried out in chlorobenzene to produce Compound 4 . Compound 4 is reacted with excess chloroacetyl chloride to produce compound 5. Compound 6 can be prepared by reacting compound 5 directly with anhydrous aluminum trichloride for two hours. Compound 7 was hydrolyzed by ring-opening in ethanol solution of sodium hydroxide to prepare compound 7. The method is simple and easy to operate, and the obtained diclofenac sodium is of high purity, but the catalyst triphenylphosphine is relatively expensive. The condensation reaction of the second step compound 2 to compound 3 requires the use of titanium tetrachloride as the solvent, but the ratio of the titanium tetrachloride has a certain effect on the yield of the compound 2, and the yield of the synthetic route is low, as shown in Figure 3 [11].

\subsection{O-iodophenylacetic Acid Route}

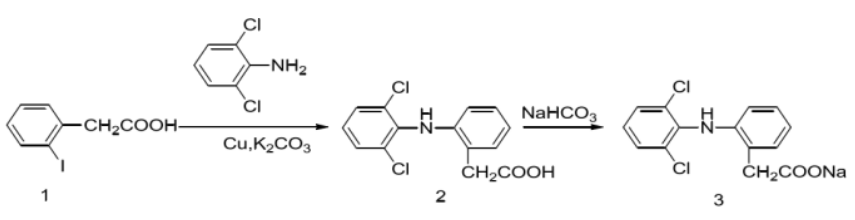

Figure 4: Route map for the synthesis of o-iodophenylacetic acid

Some pharmaceutical companies in China adopt this route and the total yield exceeds $30 \%$. The method uses copper powder and potassium carbonate as a catalyst to cause condensation reaction of 0 iodophenylacetic acid with 2,6-dichloroaniline. The key to this method is that the associated yield is still not high enough, and it needs to be separated by silica gel column chromatography. The operation is more complex and there is still a need to find high-efficiency catalysts and improve the reaction conditions, as shown in Figure 4. If the yield can be improved, the profit is more ideal [9].

\subsection{0-aminophenylacetic Acid Route}
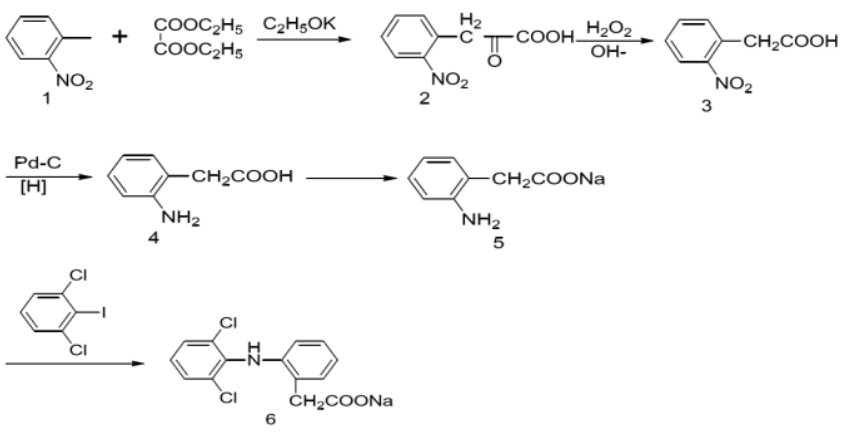

Figure 5: Route map for the synthesis of o-aminophenylacetic acid

This method has many reaction steps, and the reaction operation is rigorous. When using potassium ethoxide in the first step, water-free operation must be ensured. The method used for nitro reduction is contact hydrogenation, the compound 4 is unstable, and it is prone to selfdehydration and condensation to generate 2-hydroxyindole, as shown in Figure 5. Simultaneously, the synthesis of dichloroiodobenzene is also complicated [10].

\subsection{Indolone Route}

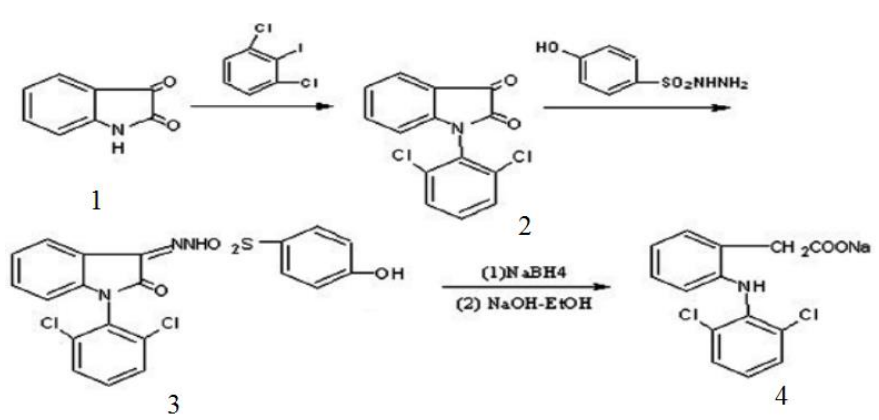

Figure 6: Route map for the synthesis of indolone

This method has a yield of more than $50 \%$ in the indolone method, the reaction conditions are not harsh, the operation is also simple, and the raw materials are easily available, which is one of the ideal routes [12] Compound 1, also known as Isatin, is a dye that has some toxicity. The International Agency for Research on Cancer at the World Health Organization defined Isatin as a class 3 carcinogen, as shown in Figure 6. This is also the most undesired place for this method. 
4.5 Aniline Route
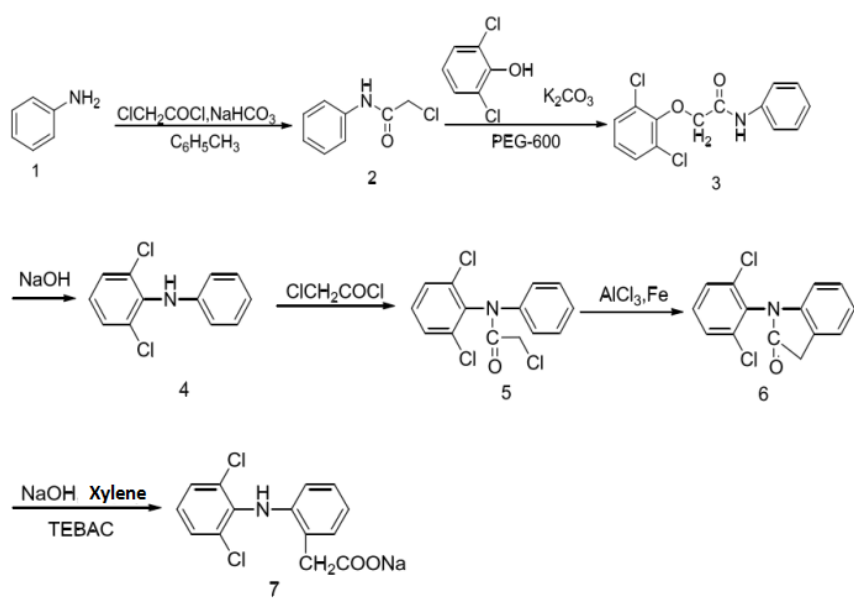

Figure 7: Route map for the synthesis of aniline

Using aniline as the starting material, the key intermediate 2,6dichlorodiphenylamine was synthesized through three steps of chloroacylation, condensation and rearrangement reactions. Compound 7 can then be prepared by continuing the ring opening by chloroacetylation, cyclization and hydrolysis reactions. The method is simple and easy to synthesize the target compound, and the yield is high, which can reach more than $80 \%$. However, toluene is used as solvent in the system prior to the synthesis of compound 4, while toluene belongs to precursor chemicals, which has some problems in purchase and management, as shown in Figure 7. If the solvent substitution problem is solved, this synthesis method will be ideal [13].

\subsection{Other Routes}

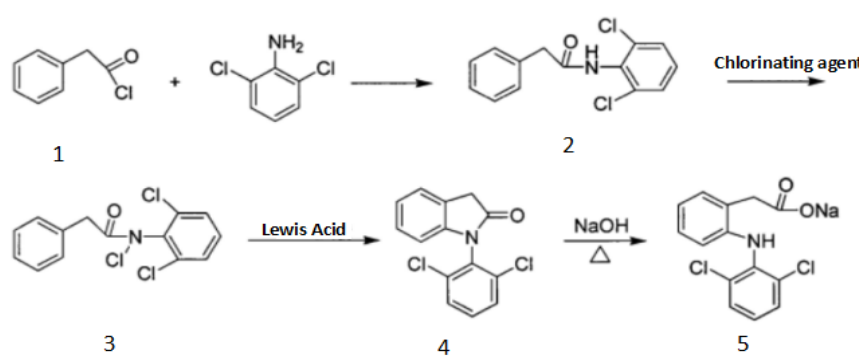

Figure 8: Route map for the synthesis of other

This method has the characteristics of easy availability of raw materials, low cost, simple operation, mild conditions, high yield, and simple postprocessing. However, it is difficult to purify the product by adding chlorination agent in the process of synthesizing compound 3 , as shown in Figure 8 [14].

In summary, although cyclohexanone is used as the starting material in the cyclohexanone route, 2,6-dichlorodiphenylamine can be obtained in a relatively high purity, but the process is complicated, the pollution is serious, and the three wastes are difficult to handle. In some areas, the environmental protection departments have taken tough measures to prohibit the production of this process and have been gradually eliminated. The o-iodophenylacetic acid route, the o-aminophenylacetic acid route and the fluorenone route all use 2,6-dichloroiodobenzene. When it is synthesized, iodide is produced because iodide is difficult to remove, so it will be very harmful if it is used to prepare medical products. Other route is difficult to separate because of the use of chlorination agents. The aniline route, with 2,6- two Chlorophenol and aniline as the raw material, obtained 2,6- two Chloroaniline by acylation, condensation, rearrangement and hydrolysis without separation. Then, diclofenac sodium can be prepared by chloroacetylation, cyclization and hydrolysis reaction. Because of low cost, high yield, good product quality, less waste and easy to realize industrialization and other reasons. It has been favored by manufacturers at home and abroad.

\section{SYNTHESIS OF DICLOFENAC DERIVATIVES}

Diclofenac drugs have obvious analgesic effects, good anti-inflammatory effects and rapid onset of action. At the same time, its market demand continues to increase, but currently applied diclofenac drugs have many adverse reactions. In order to meet market demand and reduce adverse reactions, a series of improved experiments are needed to screen for diclofenac drugs with fewer adverse reactions.

\section{1 synthesis route of diclofenac esters}

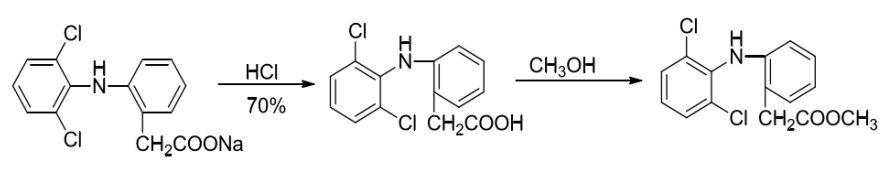

Figure 9: Synthesis route map of diclofenac methyl ester

Using aniline and 2,6-dichlorophenol as starting materials, the key intermediate 2,6-dichlorodiphenylamine was synthesized through chloroacylation reaction, etherification reaction and rearrangement reaction. The resulting key intermediate 2,6-dichlorodiphenylamine is further passed through acylation reaction, cyclization reaction and hydrolysis reaction to synthesize diclofenac sodium. According to reference, diclofenac sodium can be acidified with hydrochloric acid, and then diclofenac can be reacted with methanol to produce diclofenac methyl ester as the target product, with a total yield of about $46 \%$, as shown in Figure 9 [15-17]. Ethyl diclofenac and n-butyl diclofenac can also be obtained by reacting anhydrous ethanol and $n$-butanol with diclofenac.

\section{2 synthesis route of diclofenac choline}

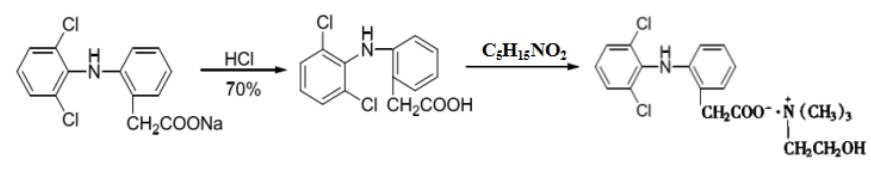

Figure 10: Synthesis route map of diclofenac choline

By consulting the literature, diclofenac sodium is acidified with hydrochloric acid and then added to choline, and diclofenac choline can be generated at $50^{\circ} \mathrm{C}$ for a period of time, the yield of diclofenac is about $75 \%$, as shown in Figure 10 [17]. Compared with the literature, this method saves a lot of reaction time, greatly shortens the production cycle, saves the reagents, the product has high purity, good color, no industrial pollution, and is easy to produce in large quantities [18].

\subsection{Synthesis route of other diclofenac salts}

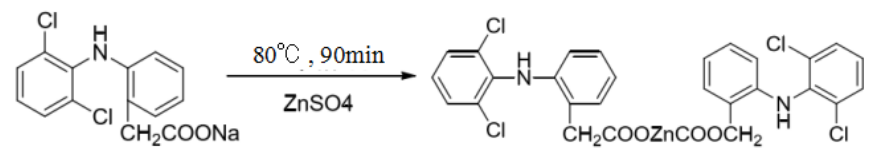<smiles>CC(=O)OCc1ccccc1Nc1cc(Cl)c(C(=O)OCc2ccccc2)cc1Cl</smiles>

Figure 11: Synthesis route map of other diclofenac salts

The conditions used for the synthesis of diclofenac are the reaction of diclofenac sodium and sulphate in a water bath at $80^{\circ} \mathrm{C}$ for 90 minutes, and the yield is about $60 \%$, as shown in Figure 11. The selection of metal ions is mostly trace elements required by the human body, such as copper and zinc. Copper is an essential trace element in the human body. It is a component of many metalloenzymes. Copper-containing enzymes play a major role in the human body and have important physiological functions. Zinc is an essential trace element in the human body. It not only participates in the formation of many metalloenzymes in the human body, but also has important physiological functions such as maintaining normal body metabolism, promoting growth and development, promoting appetite, and participating in immune function. Copper and zinc are 
relatively less toxic than other metals and are easily coordinated with ligands containing nitrogen and oxygen to form stable complexes, which are cheap and easy to obtain. Many copper complexes can kill cancer cells, scavenge free radicals, prevent the formation and development of cancer, and scavenge reactive oxygen species [19-22].

\section{CONCLUSION}

In summary, diclofenac derivatives are better than diclofenac sodium in terms of efficacy and side reactions, and the synthesis process is also very simple. However, regardless of which derivative is synthesized, it is necessary to synthesize the key intermediate of diclofenac sodium in the first. Therefore, whether diclofenac sodium is used as an intermediate or a final product, its market usage will continue to increase with the continuous development of diclofenac analgesics. Diclofenac has significant antipyretic, analgesic, and anti-inflammatory effects with fewer adverse reactions. Its characteristics can be summarized as quick-acting, analgesic, anti-inflammatory, antipyretic, powerful analgesia, less addictive, complete absorption, no savings, rapid onset, widely applicable. It is precisely because of this product has many of the above advantages, so its performance in the domestic market in recent years is strong, with great potential for development and a good market prospects.

\section{ACKNOWLEDGMENTS}

Thanks to my tutor, Professor Liu Yanjie, she has been greatly assisted in my studies and life for more than a year. The profound knowledge, keen insight, and rigorous scholarship of the teacher inspired my passion for learning. I have made great progress in experimental skills and thinking methods. The tutor has set an example for me so that I can better find my own problems and seek help, correct them, and allow myself to walk more smoothly in the future.

\section{REFERENCES}

[1] Inotai, A., Hanko, B., Meszaros, A. 2010. Trends in the non-steroidal antiinflammatory drug market in six Central-Eastern European countries based on retail information. Pharmacoepidemiol Drug Saf, 19 (2), 183.

[2] MeEvog, A., Livingstone, J., Cahill, C. 1996. Coparison of didofenat sodium and morphine sulphate for postoperative analgesia after day ease inguinal hernia surgery. AnnRCoil SurgEngl, 78 (4), 363-366.

[3] Lun, Z. 2004. The Analysis of Diclofenac Market. China Pharmacy, 15 (7), 394-396.

[4] Xuejie, W., Caiqin, G., Zhifang, Q. 2001. Pharmacological action and clinical application of diclofenac. Shandong medical industry, 20 (3).

[5] Haitong, Z., Kader, Shuson, L. 1998. Study on pharmacokinetics and bioavailability of oral Diclofenac Potassium Capsules. Chinese Journal of clinical pharmacology, 14 (1), 44-46.

[6] Yawei, L. 2008. Synthesis and anti-inflammatory and analgesic activities of diclofenac potassium and its derivatives. Chinese excellent master dissertation database.
[7] Chunhong, L. 2004. Diclofenac choline analysis method research. China excellent master's thesis full text database.

[8] Sato, H., Miyagawa, Y., Okabe, T. 1997. Dissolutionmechanism of dielofenae sodium from wax matrix granules. Pbarra Sci, 86 (8), 929-934.

[9] Lipsky, P. 1997. Cyclooxygenas reseach: advance with clinical implacations. Emery P.Rheuma-tologyhighlights. Oadord Health Press, 24.

[10] Feisheng, Q. 1979. antipyretic analgesic anti-inflammatory drugs diclofenac synthesis. pharmaceutical industry, (11), 14-18.

[11] Bingchang, Q., Jing, C., Xincheng, L. 2008. Research on the synthesis technology of diclofenac sodium. Applied Chemistry, 37 (03), 275-278.

[12] Jingni, W. 2013. Market analysis and synthesis research of diclofenac sodium. Advances in Medicine, 32 (11), 166-167.

[13] Fen, C., Jiangling, W., Sheng, G.C. 1995. Study on the synthesis of diclofenac sodium. Chinese Journal of pharmaceutical industry, 26 (4), 145-147.

[14] Xingtao, T., Lijun, R., Lian, X.Y. 2013. A preparation method of diclofenac sodium, CN, 103145574.

[15] Fen, C., Yan, D., Li, H.Y. 1988. Diclofenac sodium, the synthetic process II substituted acetanilide rearrangement. Chinese Journal of pharmaceutical industry, 29 (8), 339-340.

[16] Hanzhu, L., Wenhua, C., Shouyu, Y. 1994. Preparation and determination of diclofenac sodium lysine. Journal of Yanbian Medical College, 17 (2), 126-128.

[17] Lie, L., Suqing, Y., Jie, L. 2000. The preparation of diclofenac choline. Journal of Henan Medical University, 35 (5), 443-444.

[18] Faraka, S.R., Petrarca, V. 1993. Preparation of diclofenac cholinesalt. Eur Pat, Appl EP, 521393.

[19] Marzano, C., Pellei, M., Tisato, F. 2009. Copper complexes as anticancer agents. Anti-cancer agents in medicinal chemistry, 9 (2), 185211.

[20] Shaikh, M.M., AlSuhaimi, A.O., Hanafiah, M.M., Ashraf, M.A., Fantoukh, A., AlHarbi, E. 2017. Leachable Volatile Organic Compounds from Polyethylene Plumbing Plastic Pipes: a case study of Medina Al Munawarah, Saudi Arabia. Acta Chemica Malaysia, 1 (1), 01-03.

[21] Cho, T. 2017. Innovative Micro-Dust Reduction Technologies. Acta Chemica Malaysia, 1 (1), 04-07.

[22] Aldaihani, N., Alenezi, R. 2017. Estimation of CO2 Emissions of The Vehicles Transport Sector In The State Of Kuwait. Acta Chemica Malaysia, $1(1), 08-12$.

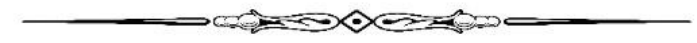

